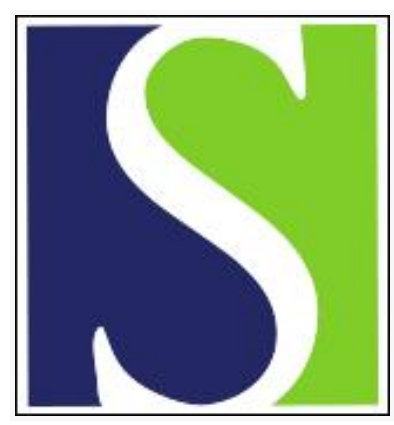

Scand J Work Environ Health 1991;17(5):318-323

https://doi.org/10.5271/sjweh.1696

Issue date: Oct 1991

Congenital malformations and exposure to high-frequency electromagnetic radiation among Danish physiotherapists. by Larsen Al

Affiliation: Department of Occupational Medicine, Central Hospital, Esbjerg, Denmark.

This article in PubMed: www.ncbi.nlm.nih.gov/pubmed/1947917

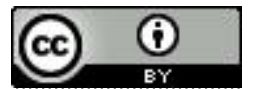




\title{
Congenital malformations and exposure to high-frequency electromagnetic radiation among Danish physiotherapists
}

\author{
by Anders I Larsen, MD'
}

\begin{abstract}
LARSEN AI. Congenital malformations and exposure to high-frequency electromagnetic radiation among Danish physiotherapists. Scand J Work Environ Health 1991;17:318-23. A cluster initiated the present case-referent study to assess the relation between exposure to high-frequency electromagnetic radiation and congenital malformations. Through the linkage of a cohort formed from a union file of Danish physiotherapists with complete national registers of pregnancy outcome, cases (pregnancies terminated by the birth of a malformed child) and referents were identified. From responses in a blinded telephone interview without knowledge of case status, exposure to high-frequency electromagnetic radiation in the first month of pregnancy was assessed. Indices reflecting duration of exposure ("time") and maximum level of exposure ("peak") were composed. After a $7 \%$ dropout 54 cases and 247 referents were interviewed. No statistically significant associations between pregnancy outcome and high-frequency electromagnetic radiation were found (odds ratio $1.7,95 \%$ confidence interval $0.6-4.3$ ).
\end{abstract}

Key terms: case-referent study, short-wave diathermy.

High-frequency electromagnetic radiation is radiation in the frequency range between $300 \mathrm{kHz}$ and $300 \mathrm{MHz}$. Important occupational sources of radiation are shortwave diathermy in health services, glue hardening, plastic welding, radar technology, and telecommunication. "These sources appear to be a highly significant occupational exposure due to both the magnitude of the fields and the frequency range, which is close to the human whole-body resonance [p 141]"' (1). However, while the exposure levels very often exceed current protection standards $(1,2)$, the hazard from exposure to high-frequency electromagnetic radiation is still uncertain. Most epidemiologic studies have not shown any hazards (1). However, many studies may suffer from a risk of exposure misclassification, which would weaken the strength of detection of the studies.

In Denmark, a cluster of four cases of congenital malformation among 25 pregnancies of a staff of physiotherapists exposed to high-frequency electromagnetic radiation during pregnancy (3) initiated this study. The first case was a girl born at term with a birthweight of $3200 \mathrm{~g}$ and with hemihypertrophy. The second was a stillborn, dysmature girl weighing $1500 \mathrm{~g}$ and showing several major malformations of the central nervous system, the gastrointestinal tract, and the kidneys. Case number three was a mature boy weighing $4200 \mathrm{~g}$ with transposition of the great vessels. Finally, the fourth case was a premature, thanatophoric girl, who died perinatally. Her birthweight was $2090 \mathrm{~g}$. 1 Department of Occupational Medicine, Central Hospital,
Esbjerg, Denmark.

Reprint requests to: Dr AI Larsen, Occupational Health Service, Novo Nordisk, Novo Allé, DK-2880 Bagsvaerd, Denmark.
The aim of the study was to assess the possibility that exposure to high-frequency electromagnetic radiation increases the frequency of detectable congenital malformations at the time of birth.

From the cohort forming the basis of the present study another paper (4) has focused on high-frequency electromagnetic radiation in relation to pregnancy outcomes other than malformations.

\section{Subjects and methods}

\section{Study design}

Pregnancies among Danish physiotherapists formed the object of the study, which was designed as a casereferent investigation nested within a cohort formed from the files of the Union of Danish Physiotherapists. Through computerized linkage with national registers of births, congenital malformations, and hospital admissions, the cases and referents were identified, and, subsequently, information on prenatal exposure to high-frequency electromagnetic radiation was obtained through telephone interviews.

\section{Subjects}

Ninety-eight percent of all employed physiotherapists are members of the Union of Danish Physiotherapists. Women, born in 1933 or later, and joining the union since 1978 or later were entered into the cohort. Through the use of their civil registration numbers, members of the cohort were linked with the national register of births, which identified women giving birth from 1978 to 1985 and provided data on parity and place of birth.

Information on malformations came from the following three sources: (i) malformations appearing at 
birth and recorded in the national register of births by the midwives, (ii) information on diseases - including congenital malformations - resulting in hospital admissions recorded in the national register on hospital admissions by physicians, and (iii) the national register on congenital malformations, established in 1983. Hospital physicians must report cases of congenital malformation appearing in the first year of life to the last-mentioned register. The registers were scanned from 1978 through 1985 , the malformation register, however, being checked from 1983 on.

Without a doubt, all births were identified, and most of the diagnosed malformations were recorded.

Cases were defined as pregnancies resulting in the birth of children with one or more congenital malformations listed in one of the registers (codes 740759.99 of the International Classification of Diseases, excluding dislocation of the hips). The reference group consisted of noncase children identified in a random unmatched sample of pregnancies coming from the cohort. The size of this sample corresponded with the number of malformed cases added to the number of cases, explained in the study of pregnancy end points other than malformations (4).

According to the inclusion criteria, 4064 members of the Union of Danish Physiotherapists should have entered the study. Forty-three women $(1 \%)$ could not be identified by the civil registration number. The remaining 4021 women gave birth to 1580 children after the exclusion of 17 pairs of twins. For the casereferent study 57 cases were identified in the registers and 267 referents were traced. Five percent of the cases and $7 \%$ of the referents could not be reached by telephone or letter. (This dropout was not statistically related to case status, $P=0.8$, Fisher's exact test.) No one explicitly refused to participate in the telephone interview.

\section{Exposure estimation}

Information on exposure to high-frequency electromagnetic radiation was obtained through telephone interviews, performed by the author and without knowledge of the case status of the respondent. The recording of exposure data was based on experience from a pilot study which showed that physiotherapists' exposure to high-frequency electromagnetic radiation during diathermic treatment could be assessed with some accuracy from telephone interviews (2).

As a month in the beginning of pregnancy easy to recall, the first month was chosen as a point of focus for the interview. The interview included questions on main job tasks and, especially, a detailed interrogation concerning the use of high-frequency electromagnetic radiation (short-wave equipment).

In principle, the level of the physiotherapist's exposure to high-frequency electromagnetic radiation is a function of variations in the distance between the electrode producing the radiation and the operator and the type of electrode.

Short-wave electrodes can be ranked according to the magnitude of irradiation. Work with or close to $(<2 \mathrm{~m})$ circuplodes, diplodes, and plate electrodes implies weak, intermediate, and high exposure, respectively. The electrode quotients can, with some certainty, be estimated to be about 1:100:1000 (2). As only few women were exposed to the very low emitting circuplode, the electrode factor was divided into the following three categories: $0=$ no exposure or exposure only to circuplodes, $1=$ work with or close to $(<2 \mathrm{~m})$ diplodes, and $10=$ work with or close to $(<2 \mathrm{~m})$ plate electrodes.

Variation in the exposure time was recorded as (i) the duration of time spent per week in the room of the clinic with high-frequency electromagnetic radiation and (ii) the frequency with which high-frequency electromagnetic radiation was used in the clinic $(0=$ less than daily, $1 / 4=$ daily but less than once per hour, $1 / 2=$ daily once or twice per hour, and $\mathbf{1}=$ more than twice per hour).

It was not considered possible to obtain valid data on the variations in the distance between the used electrode and the operator, except that this parameter was taken into account indirectly in the electrode factor, as has already been mentioned.

In the case-referent analysis two measures of exposure were used. First, the electrode factor alone expressed the maximum level of exposure ("peak"). Second, multiplying the three factors magnitude of irradiation, duration, and frequency produced a timeweighted expression of the exposure ("time"). This product was also divided into three classes as none, low, and high exposure.

\section{Confounders}

At the end of the telephone interview, the physiotherapist was asked about her consumption of tobacco and alcohol during pregnancy (both at five levels), ultrasound use during the first month of pregnancy (binary variable), diseases during pregnancy, and use of legal drugs during the first month of pregnancy (binary variables). Other potential confounders were parity, age, place of child's birth (as diagnostic criteria for congenital malformations probably vary among different categories of hospitals), and year of pregnancy termination (as the frequency with which highfrequency electromagnetic radiation is used could have changed during the study period and as the register of malformations was initiated in the middle of the period).

\section{Statistics}

Crude relationships between pregnancy outcome and exposure to high-frequency electromagnetic radiation were estimated from the odds ratio (OR) and the exact $95 \%$ confidence interval $(95 \% \mathrm{CI})(5)$. The con- 
Table 1. Frequency of congenital malformations according to the level of duration of exposure (time index). Effect estimation by the crude and gender-specific odds ratio (OR). (95\% Cl=95\% confidence interval)

\begin{tabular}{|c|c|c|c|c|c|c|c|c|c|}
\hline \multirow{2}{*}{ Time index ${ }^{a}$} & \multicolumn{2}{|c|}{ Malformation } & \multicolumn{2}{|c|}{ Boys } & \multicolumn{2}{|c|}{ Girls } & \multicolumn{2}{|c|}{$\begin{array}{l}\text { Boys and girls } \\
\text { combined }\end{array}$} & \multirow{2}{*}{$\begin{array}{l}\text { Test for } \\
\text { heterogeneity } \\
\text { between } \\
\text { genders } \\
\text { (P-value) }\end{array}$} \\
\hline & $\begin{array}{l}\text { Refer- } \\
\text { ence } \\
\text { group }\end{array}$ & $\begin{array}{l}\text { Case } \\
\text { group }\end{array}$ & OR & $95 \% \mathrm{Cl}$ & OR & $95 \% \mathrm{Cl}$ & OR & $95 \% \mathrm{Cl}$ & \\
\hline $\begin{array}{l}0 \\
1 \\
2\end{array}$ & $\begin{array}{r}193 \\
36 \\
18\end{array}$ & $\begin{array}{r}39 \\
9 \\
6\end{array}$ & $\begin{array}{l}1.0 \\
1.0 \\
1.5\end{array}$ & $\begin{array}{c}0.2-3.5 \\
0.2-8.2\end{array}$ & $\begin{array}{l}1.0 \\
2.0 \\
2.4\end{array}$ & $\begin{array}{c}0.6-6.1 \\
0.6-8.6\end{array}$ & $\begin{array}{l}1.0 \\
1.2 \\
1.6\end{array}$ & $\begin{array}{c}0.5-2.7 \\
0.6-4.3\end{array}$ & $\begin{array}{c}. \\
0.4 \\
0.7\end{array}$ \\
\hline Test for trend & \multicolumn{4}{|c|}{$P=0.70$} & $P=0.12$ & \multicolumn{3}{|c|}{$P=0.29$} & \\
\hline
\end{tabular}

a $0=$ no exposure, 1 = low exposure, 2 = high exposure.

Table 2. Frequency of congenital malformations according to the level of peak exposure (peak index). Effect estimation by the crude and gender-specific odds ratio (OR). (95\% Cl=95\% confidence interval)

\begin{tabular}{|c|c|c|c|c|c|c|c|c|c|}
\hline \multirow{2}{*}{ Peak index ${ }^{a}$} & \multicolumn{2}{|c|}{$\begin{array}{l}\text { Malformation } \\
(\mathrm{N})\end{array}$} & \multicolumn{2}{|c|}{ Boys } & \multicolumn{2}{|c|}{ Girls } & \multicolumn{2}{|c|}{$\begin{array}{l}\text { Boys and girls } \\
\text { combined }\end{array}$} & \multirow{2}{*}{$\begin{array}{c}\text { Test for } \\
\text { heterogeneity } \\
\text { between } \\
\text { genders } \\
\text { (P-value) }\end{array}$} \\
\hline & $\begin{array}{l}\text { Refer- } \\
\text { ence } \\
\text { group }\end{array}$ & $\begin{array}{l}\text { Case } \\
\text { group }\end{array}$ & OR & $95 \% \mathrm{Cl}$ & OR & $95 \% \mathrm{Cl}$ & OR & $95 \% \mathrm{Cl}$ & \\
\hline $\begin{array}{l}0 \\
1 \\
2\end{array}$ & $\begin{array}{r}178 \\
13 \\
56\end{array}$ & $\begin{array}{r}37 \\
3 \\
14\end{array}$ & $\begin{array}{l}1.0 \\
0.0 \\
1.3\end{array}$ & $0.5-3.3$ & $\begin{array}{l}1.0 \\
3.1 \\
1.5\end{array}$ & $\begin{array}{l}0.6-13.7 \\
0.5-4.3\end{array}$ & $\begin{array}{l}1.0 \\
1.1 \\
1.2\end{array}$ & $\begin{array}{c}\cdot \\
0.2-3.9 \\
0.6-2.4\end{array}$ & $\begin{array}{l}. \\
0.1 \\
0.8\end{array}$ \\
\hline Test for trend & & & $P=0.75$ & & $P=0.40$ & & $P=0.59$ & & \\
\hline
\end{tabular}

a $0=$ no exposure, $1=$ low exposure, $2=$ high exposure.

Table 3. Frequency of congenital malformations of the heart according to the level of duration of exposure (time index). Effect estimation by the odds ratio (OR). ( $95 \% \mathrm{Cl}=95 \%$ confidence interval)

\begin{tabular}{|c|c|c|c|c|}
\hline \multirow{2}{*}{ Time index ${ }^{a}$} & \multicolumn{2}{|c|}{$\begin{array}{l}\text { Malformation } \\
\text { of the heart } \\
\text { (N) }\end{array}$} & \multirow{2}{*}{ OR } & \multirow{2}{*}{$95 \% \mathrm{Cl}$} \\
\hline & $\begin{array}{l}\text { Refer- } \\
\text { ence } \\
\text { group }\end{array}$ & $\begin{array}{l}\text { Case } \\
\text { group }\end{array}$ & & \\
\hline $\begin{array}{l}0 \\
1 \\
2\end{array}$ & $\begin{array}{r}199 \\
37 \\
20\end{array}$ & $\begin{array}{l}7 \\
1 \\
2\end{array}$ & $\begin{array}{l}1.0 \\
0.8 \\
2.8\end{array}$ & $\begin{array}{c}\cdots b \\
0.4-13.7\end{array}$ \\
\hline
\end{tabular}

Test for trend

$P=0.32$

a $0=$ no exposure, $1=$ low exposure, $2=$ high exposure.

b Not calculated due to the few cases in one cell.

Table 4. Frequency of congenital malformations of the heart according to the level of peak exposure (peak index). Effect estimation by the odds ratio (OR). ( $95 \% \mathrm{Cl}=95 \%$ confidence interval)

\begin{tabular}{|c|c|c|c|c|}
\hline \multirow{2}{*}{ Peak index } & \multicolumn{2}{|c|}{$\begin{array}{l}\text { Malformation } \\
\text { of the heart } \\
\text { (N) }\end{array}$} & \multirow{2}{*}{ OR } & \multirow{2}{*}{$95 \% \mathrm{Cl}$} \\
\hline & $\begin{array}{l}\text { Refer- } \\
\text { ence } \\
\text { group }\end{array}$ & $\begin{array}{l}\text { Case } \\
\text { group }\end{array}$ & & \\
\hline $\begin{array}{l}0 \\
1 \\
2\end{array}$ & $\begin{array}{r}184 \\
14 \\
58\end{array}$ & $\frac{6}{4}$ & $\begin{array}{l}1.0 \\
0.0 \\
2.1\end{array}$ & $0.5-8.0$ \\
\hline Test for trend & \multicolumn{4}{|c|}{$P=0.28$} \\
\hline
\end{tabular}

a $0=$ no exposure, $1=$ low exposure, 2 = high exposure. founders were evaluated in logistic regression models. Mantel-Haenszel statistics were applied in the analysis stratifying for gender and in the trend analysis (6).

\section{Results}

Overall, the frequency of malformations was $3.6 \%$, and for cardiac malformations the occurrence was $0.7 \%$.

The crude associations between the indices of exposure to high-frequency electromagnetic radiation and the occurrence of malformation (tables 1 and 2) were weak and not statistically significant, as the confidence intervals were wide and included unity. The genderspecific figures indicated that the risk seemed greater for girls than for boys although the tests for heterogeneity were negative. No statistically significant trends could be demonstrated.

When the analysis focused on the occurrence of malformations of different organs, due to the small figures, only data on cardiac malformations provided some information (tables 3 and 4). Again the confidence intervals included unity, but the odds ratio tended to be a little higher than for malformations as a whole. Variation by gender across the strata could not be interpreted in detail, as the data were sparse.

Logistic regression models controlling for the potential confounders, including work with ultrasound equipment, did not explain the variation statistically significantly better than the crude models, consequent- 
ly the results of the crude models are presented. Thus, in the optimum models, the effect estimates remained at the same level as the crude estimates. For example, while, for the girls, the crude odds ratio for time at the highest level of exposure was 2.4 (95\% CI 0.68.6), the adjusted figures were 2.0 (95\% CI 0.5-8.1) in the optimum model.

Analyzing the components of the indices of exposure to high-frequency electromagnetic radiation revealed inconsistent relationships between outcome and exposure.

\section{Discussion}

When a biological organism is exposed to an electromagnetic field, an internal field is induced within the object. The magnitude and the distribution of the internal electromagnetic energy depend on the relation between the magnitude, frequency, and direction of the external field and the size, shape, and anatomy of the body. Furthermore, depending on the dielectric properties of the tissues, internal field energy is converted into thermal energy and perhaps results in a local or systemic rise in temperature, depending on the capacity of the local and systemic thermoregulatory systems (1).

When pregnant animals are exposed to thermal levels of high-frequency electromagnetic radiation, the dose, the rise in temperature, and the frequency of malformations in the offspring correlate and are consistent with the assumption that the teratogenicity of high-frequency electromagnetic radiation could be a consequence of hyperthermia induced by the field.

Although occupational exposure limits should be well below exposure levels able to induce a general rise in temperature, in fact the norms are often exceeded $(1,2)$. Furthermore, energy from high-frequency electromagnetic radiation is always deposited heterogeneously in the exposed organism. In other words, a lack of increase in whole-body temperature does not exclude local heating ("hot spots"). In addition, at least two animal studies $(7,8)$ have indicated that the mechanism of the effect of high-frequency electromagnetic radiation on the development of malformations might not only be thermal. It was hypothesized that the teratogenicity is a property of the radiation itself. If so, the occupational exposure limit should not be based on thermal models only. One of the aforementioned studies (8) presented the hypothesis that exposure time plays an important role in inducing birth defects. In conclusion, experimental evidence suggests that high-frequency electromagnetic radiation has a teratogenic property, and it cannot be excluded that this property might also be present under exposure conditions existing in occupational environments. For the evaluation of this hazard epidemiologic evidence is highly desirable.

Workers in professions other than physiotherapy may be exposed to high-frequency electromagnetic radiation, and even at a greater magnitude than physiotherapists (eg, in plastic welding and glue hardening). However, as the exposure situation for these groups usually also includes chemical exposures which could confound the effects of high-frequency electromagnetic radiation, physiotherapists became the object of the present study.

In the present case-referent study the association between high-frequency electromagnetic radiation and the occurrence of congenital malformations was weak and not statistically significant, as the confidence intervals were wide and included unity. Simple doseresponse relationships (tables 1 and 2) could be indicative of a causal relationship, but no significant trend appeared. Unfortunately, as the knowledge of the interaction between high-frequency electromagnetic radiation and biological organisms is sparse, it was not possible to construct more sophisticated models including scales to make the trend analyses more sensitive. The outcome of the trend analyses remained virtually unaffected by changes in the exposure scale.

The observed tendency towards a difference in risk between boys and girls was striking, but again it was only a tendency. Since congenital malformations at birth are seen only for those who survive fetal life, male fetuses might be vulnerable to high-frequency electromagnetic radiation and thus survive with a malformation to a less extent than female fetuses after exposure to high-frequency electromagnetic radiation (4). If so, only the observed dose-response relationship for the females reflects the true risk of malformation. Alternatively, if high-frequency electromagnetic radiation is truly not teratogenic, an explanation for the observed difference in the gender-specific risk might still be that the males are more vulnerable to high-frequency electromagnetic radiation, and therefore the tendency towards an excess risk for females when compared with males is false positive. Only studies revealing information on gender and malformations of aborted fetuses in relation to exposure data could clarify these questions. The data in this study are not sufficiently informative to be conclusive in this respect.

The two exposure indices "peak" and "time" should represent alternative views of the mode of action of high-frequency electromagnetic radiation. The time index is a time-modified version of the peak index, which only estimated the maximum instantaneous level of exposure.

From the point of view of information bias, the peak index is undoubtedly the most reliable, as this parameter is only based on information on the type of equipment (electrode) used by the physiotherapist. Apparently, most of the physiotherapists did not know of differences in emission from different types of electrodes. The time index was more sensitive to information bias, as this parameter was also influenced by information on duration of exposure and the frequency with which high-frequency electromagnetic radiation was used in the clinic. Thus information bias could be 
Table 5. Comparison of three case-referent studies, including the present study on congenital malformations and reported exposure to high-frequency electromagnetic radiation (OR = odds ratio, $95 \% \mathrm{Cl}=95 \%$ confidence interval)

\begin{tabular}{|c|c|c|c|c|c|}
\hline \multirow{3}{*}{ Study } & \multicolumn{5}{|c|}{ Level of exposure ${ }^{a, b}$} \\
\hline & \multirow{2}{*}{$\frac{0}{O R}$} & \multicolumn{2}{|r|}{1} & \multicolumn{2}{|r|}{2} \\
\hline & & OR & $95 \% \mathrm{Cl}$ & OR & $95 \% \mathrm{Cl}$ \\
\hline $\begin{array}{l}\text { Kăllén et al, } 1981(9) \\
\text { Taskinen et al, } 1990(10) \\
\text { Present study (table 1) }\end{array}$ & $\begin{array}{l}1.0 \\
1.0 \\
1.0\end{array}$ & $\begin{array}{l}0.4 \\
2.3 \\
1.2\end{array}$ & $\begin{array}{l}0.1-1.2 \\
1.1-4.7 \\
0.5-2.7\end{array}$ & $\begin{array}{l}2.0 \\
1.0 \\
1.7\end{array}$ & $\begin{array}{l}0.7-6.2 \\
0.3-3.0 \\
0.6-4.3\end{array}$ \\
\hline
\end{tabular}

responsible for the "time" association exceeding the "peak" estimates. Alternatively, the findings support the hypothesis (8) that exposure time is important with respect to teratogenic risk.

Exposure information was gathered without knowledge of the case status of the respondent, but the hypothesis of a hazard of high-frequency electromagnetic radiation may have been known by some of the physiotherapists beforehand. Consequently, information bias constituted a potential problem. However, bias was not revealed in another study (4) originating from the same cohort, since low odds ratios were estimated, for example, in relation to low birthweight among girls as opposed to statistically significantly elevated odds ratios for boys. A crude odds ratio of 0.8 between ultrasound use during pregnancy and birth of a malformed child in the present study also speaks against a general tendency towards information bias in the study population.

In contrast to information bias leading to a differential misclassification of exposure, nondifferential misclassification of exposure always pulls the risk estimates towards null and widens the confidence intervals, and some major sources of misclassification should be considered. Uncertainties with respect to retrospective interview data and exposure indices which may easily miss the proper exposure window in the time of pregnancy progression represented the main sources of nondifferential misclassification in this study. Beforehand, it was considered impossible to obtain valid data on variations in distance between the high-frequency electromagnetic radiation electrode and the operator, and ignoring this factor contributed to the misclassification of exposure. Furthermore, as timing is crucial in the teratogenic process, exposure information should be gathered for the narrow time interval relevant to the birth defect in question. Such information is unattainable in a retrospective study, especially when the internal exposure switches on and off synchronously with the external exposure, which typically differentiates the physical exposure situation from the chemical.

None of the confounders considered in the analysis can explain the tendencies in the study (eg, consump- tion of alcohol or tobacco, intake of medicine, diseases, age, parity, year of pregnancy, place of child's birth, or ultrasound use during pregnancy).

Two other studies $(9,10)$ concerning high-frequency electromagnetic radiation (exposure among physiotherapists) and congenital malformations in offspring have been published. Both studies were case-referent investigations comparing exposure information from questionnaires with information on pregnancy outcome from public registers. The gender distribution of the offspring is not stated in the papers. One study (9) classified exposure from the frequency with which high-frequency electromagnetic radiation was used; the other (10) used the duration of exposure. A distinction was not made between different electrodes.

In an attempt to compare the outcome of the three studies, the original results have been reclassified (table 5). As the exposure scales in the three studies are probably incommensurate and as the pattern in the table is not uniform, a meta-analysis would be difficult to interpret and was not performed. In conclusion, a hypothesis of a teratogenic risk of exposure to highfrequency electromagnetic radiation could not be verified or rejected in this study, as in earlier studies. Information bias might be responsible for the borderline finding of this study however, and probably also for the outcome of the other two studies. Moreover, a misclassification of exposure information may have led to false negative results.

In future research, experimental studies should focus on the characteristics of the interaction between high-frequency electromagnetic radiation and the biological processes, and epidemiologic research is needed to verify the present findings in other occupational groups with similar exposures.

\section{Acknowledgments}

The study received financial support from the Arbejdsmiljøfondet (1986-21).

\section{References}

1. Suess MJ, ed. Nonionizing radiation protection. Copenhagen: World Health Organization, 1980. (WHO, European series; no 10).

2. Larsen AI, Skotte J. Can exposure to electromagnetic radiation (in diathermy operators) be estimated from interview data? - a pilot study. Am J Ind Med 1991; 19:51-7.

3. Larsen AI, Jensen AO, Skotte J, Istre O. Kan ikkeioniserende stráling have indvirkning på fosterudviklingen? [Does non-ionizing radiation influence foetal development?]. Ugeskr Laeger 1987;149:518-20.

4. Larsen AI, Olsen J, Svane O. Gender-specific reproductive outcome and exposure to high-frequency electromagnetic radiation among physiotherapists. Scand J Work Environ Health 1991;17:324-9.

5. Rothman KJ. Modern epidemiology. Boston, MA: Little, Brown and Company, 1986.

6. Mantel N. Chi-square tests with one degree of freedom: extension of the Mantel-Haenszel procedure. J Am Stat 
Assoc 1963;58;690-700.

7. Berman E, Kinn JB, Carter B. Observations of mouse fetuses after irradiation with $2.45 \mathrm{GHz}$ microwaves. Health Phys 1978;35:791-801.

8. Tofani S, Agnesod G, Ossola P, Ferrini S, Bussi R. Effects of continuous low-level exposure to radiofrequency radiation on intrauterine development in rats. Health Phys 1986;51:489-99.

9. Källén B, Malmquist G, Moritz U. Delivery outcome among physiotherapists in Sweden: is non-ionizing radi- ation a fetal hazard? Arch Environ Health 1982;37: $81-5$.

10. Taskinen $\mathbf{H}$, Kyyrönen $\mathbf{P}$, Hemminki K. Effects of ultrasound shortwaves and physical exertion on the pregnancy outcome of physiotherapists. J Epidemiol Community Health (in press).

Received for publication: 18 December 1990 